\title{
Differential Effects of Morphine on Noxious Stimulus-evoked Fos-Like Immunoreactivity in Subpopulations of Spinoparabrachial Neurons
}

\author{
L. Jasmin, ${ }^{1,4,6}$ H. Wang, ${ }^{1,6}$ K. Tarczy-Hornoch, ${ }^{1,6}$ J. D. Levine, ${ }^{1,2,3}$ and A. I. Basbaum ${ }^{1,5,6}$ \\ Departments of ${ }^{1}$ Anatomy, ${ }^{2}$ Medicine, ${ }^{3}$ Oral Surgery, ${ }^{4}$ Neurosurgery, and ${ }^{5}$ Physiology, and ${ }^{6}$ Keck Center for Integrative \\ Neuroscience, University of California-San Francisco, San Francisco, California 94143
}

\begin{abstract}
In previous studies we reported that although morphine dose dependently inhibits noxious stimulus-evoked expression of the $c$-fos proto-oncogene in the rat spinal cord, morphine was without effect in certain populations of presumed nociresponsive neurons, even under conditions of complete behavioral analgesia. To determine whether the neurons that continue to express the $c$-fos gene include projection neurons, we evaluated the effect of morphine on noxious stimulus-evoked $c$-fos expression in spinoparabrachial neurons retrogradely labeled with Fluoro-gold. In the formalin test, we found that morphine analgesia was associated with a significant reduction in the number of Fos-like-immunoreactive spinoparabrachial projection neurons in the lateral reticulated area of the neck of the dorsal horn. Morphine, however, did not reduce the number of Fos-like-immunoreactive spinoparabrachial projection neurons either in the superficial dorsal horn or in the area around the central canal. These results indicate that under conditions of morphine analgesia two distinct populations of spinoparabrachial neurons can be recognized on the basis of their expression of the $c$-fos gene in response to noxious stimulation. Since the expression of the $c$-fos gene has been correlated with neuronal activity, these data suggest that activity, and central transmission of nociceptive information, persists in certain nociresponsive projection neurons during morphine analgesia. Alternatively, if activity has, in fact, been blocked in these neurons, our results indicate that injury can produce significant molecular changes in neurons even though the neuronal activity and pain associated with the injury is blocked by morphine.
\end{abstract}

IKey words: immunocytochemistry, immediate-early gene, opioid analgesia, parabrachial nucleus, formalin test, chronic pain, antinociception, rat]

Opioids produce their analgesic effect through actions at multiple sites in the CNS (Yaksh and Noueihed, 1985). At supraspinal sites, morphine binds to opioid receptors in the midbrain periaqueductal gray (PAG) and activates a descending inhibitory

\footnotetext{
Received Nov. 1, 1993; revised Apr. 26, 1994; accepted June 16, 1994.

We thank Ms. Elene Valdivia and Ms. Carmen Tam for photographic assistance. This work was supported by PHS Grants NS 14627, 21445, NIDA 08377, and the Medical Research Council of Canada (L.J.).

Correspondence should be addressed to Luc Jasmin, M.D., Ph.D., Department of Ncurosurgery, Pasquerilla Healthcare Center, Georgetown University Medical Center, 3800 Reservoir Road NW, Washington, DC 20007-2197.

Copyright (c) 1994 Society for Neuroscience 0270-6474/94/147252-09\$05.00/0
}

control systern that modulates the firing of spinal cord and trigeminal nociresponsive neurons (Basbaum and Fields, 1984). At the spinal cord level, morphine directly inhibits the firing of dorsal horn nociresponsive neurons, and it can presynaptically regulate the release of neurotransmitters from primary afferent nociceptors (Aimone and Yaksh, 1989). Although many spinal cord nociresponsive neurons that project to supraspinal sites are inhibited by opioids (Jurna and Grossman, 1976; Willcockson et al., 1984; Hylden and Wilcox, 1986; Dickenson and Sullivan, 1987), in fact it has not been established whether populations of projection neurons are inhibited during behavioral analgesia induced by systemically administered opioids.

Numerous studies have demonstrated the utility of following the expression of the $c$-fos proto-oncogene to monitor stimulation modality-specific activation of neuronal subpopulations (Hunt et al., 1987; Menétrey et al., 1989; Bullitt, 1991; Campeau et al., 1991; Brennan et al., 1992; Traub et al., 1992). For example, we recently reported that a persistent non-noxious stimulus, evoked by walking on a rotating rod for $1 \mathrm{hr}$, produces a very distinct pattern of Fos labeling in the spinal cord (Jasmin et al., 1994) that includes regions that contain neurons with predominant innocuous mechanoreceptive inputs, namely, the inner part of the substantia gelatinosa (lamina IIi), the nucleus proprius (laminae III and IV), and the medial part of the neck of the dorsal horn. In contrast to walking, noxious stimulation evokes a very different pattern of $c$-fos expression in the spinal cord (Hunt et al., 1987; Menétrey et al., 1989; Bullitt, 1990). In our studies, hindpaw formalin injection evoked increased Fos labeling in areas where physiological studies (Menétrey, 1987) have identified nociresponsive neurons: (1) the superficial laminae (I and IIo) of the dorsal horn, as defined by Molander et al. (1984), (2) the lateral reticulated area of the neck of the dorsal horn, as defined by Stciner and Turner (1972), (3) the area around the central canal, and (4) the ventral horn, in laminae VII and VIII.

Although we demonstrated that the number of Fos-like-immunoreactive neurons evoked by formalin correlates highly with the magnitude of the pain behavior that it elicited (Gogas et al., 1991), we also found that behavioral analgesia could be produced without completely blocking the formalin-induced expression of $c$-fos (Presley et al., 1990). Specifically, although morphine profoundly reduced $c$-fos expression in the reticulated area of the dorsal horn and in the ventral horn, the inhibition never exceeded $60 \%$ in the superficial dorsal horn. Our studies did not determine whether the subpopulation of dorsal horn neurons that continue to express $c$-fos during morphine anal- 
gesia includes projection neurons; all of the residual Fos-like immunoreactivity could have been in interneurons. This question is important because the neuronal circuits that could be influenced by the downstream consequences of injury-evoked $c$-fos expression under conditions of morphine analgesia are very different if the projection neurons are involved.

In the present study we specifically investigated the effects of morphine on Fos-like-immunoreactive spinal cord neurons that project to the parabrachial region. The parabrachial rather than spinothalamic projecting neurons were chosen because many of their cell bodies are located in areas of the cord where the morphine-resistant, noxious stimulus-evoked, Fos-like immunoreactivity was found, that is, in the superficial dorsal horn (laminae I and IIo). Neurons in the lateral reticulated area of the dorsal horn and in the area around the central canal (Menétrey and de Pommery, 1991; Kitamura et al., 1993) are also at the origin of the spinoparabrachial pathway. We first retrogradely labeled the spinoparabrachial neurons and then evaluated the effect of morphine on noxious stimulus-evoked Fos-like immunoreactivity in these projection neurons. We report that under conditions of behavioral analgesia, a large population of spinoparabrachial neurons continues to show increased $c$-fos expression in response to noxious stimulation.

\section{Materials and Methods}

Twenty-two male Sprague-Dawley rats (270-300 gm; Bantin and Kingman) were used in the study. All animals were exposed to light $12 \mathrm{hr} /$ d; food and water were available ad libitum. Procedures for the maintenance and use of the experimental animals conformed to the regulations of the UCSF Committee on Animal Research and were carried out in accordance with the guidelines of the NIH regulations on animal use.

To verify that injection of the tracer does not, by itself, induce $c$-fos expression, one animal received neither drugs nor nociceptive stimulation and was perfused 1 week after Fluoro-gold injection. Three animals received morphine, without noxious stimulation, and were perfused $1 \mathrm{hr}$ later to verify that the drug by itself does not induce $c$-fos expression. The 18 remaining animals underwent the formalin test (Dubuisson and Dennis, 1977) 1 week after injection of Fluoro-gold into the right parabrachial area. Twelve of the rats received morphine before the formalin injection; six controls received saline before the formalin. Two of the morphine/formalin animals also received naltrexone prior to any other treatment.

Surgery. During the surgical procedure, the animals were maintained under deep anesthesia with a mixture of ketamine $(60 \mathrm{mg} / \mathrm{kg})$ and $x y-$ lazine $(7.0 \mathrm{mg} / \mathrm{kg})$ injected intramuscularly. For surgeries that lasted more than $40 \mathrm{~min}$ an additional dose of ketamine $(20 \mathrm{mg} / \mathrm{kg})$ was given. Animals were placed in a stereotaxic apparatus (David Kopf Instruments, Germany) using nonperforating ear bars. Coordinates (rostrocaudal -0.16 , mediolateral 2.1, dorsoventral 6.3) were taken from Paxinos and Watson's (1986) atlas using the interaural point as zero. A small burr hole was made above the target, the dura matter was opened, and then $20-40 \mathrm{nl}$ of $4.0 \%$ or $8.0 \%$ Fluoro-gold (Fluorochrome Inc., $\mathrm{CO}$ ), dissolved in double-distilled water, was slowly injected into the right pontine lateral parabrachial area using a glass micropipette with a tip diameter of $40 \mu \mathrm{m}$ fixed to a $1 \mu \mathrm{l}$ Hamilton syringe. The pipette was left in place for $15 \mathrm{~min}$ after the injection to reduce tracer leakage along the injection track. After recovering from surgery, the animals were returned to the animal care facility for $7 \mathrm{~d}$, which was sufficient time for maximal retrograde transport of the Fluoro-gold to the lumbar spinal cord (Schmued and Fallon, 1986).

Formalin test. Rats were acclimated to the environment and then gently restrained and given a subcutaneous injection of $100 \mu \mathrm{l}$ of $5 \%$ formalin (Sigma, St. Louis, MO), in water, into the distal plantar region of the left hind paw; injections were made with a 30 gauge needle. The behavior of the animals was then continuously monitored for a period of $60 \mathrm{~min}$. Since we were interested in the distribution of Fos immunoreactivity under conditions of complete behavioral analgesia, we monitored the rats to ensure that the morphine effect was complete.

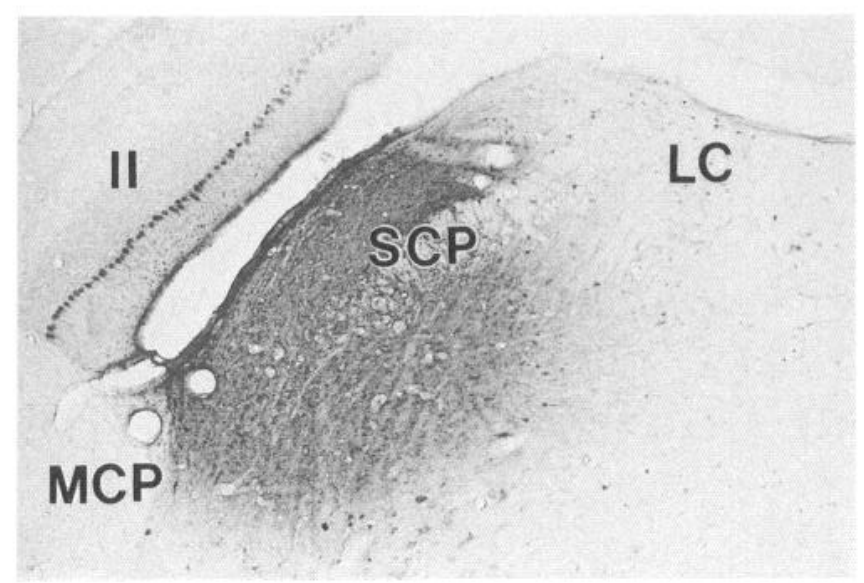

Figure 1. This photomicrograph of a transverse section through the pons illustrates the extent of the injection in the lateral parabrachial area of rat FL-129. There is moderate labeling of the adjacent lobule II $(I I)$ of the cerebellum. $L C$, locus coeruleus; $M C P$, middle cerebellar peduncle; $S C P$, superior cerebellar peduncle. Scale bar, $350 \mu \mathrm{m}$.

Drugs. Morphine sulfate (Wyeth Laboratories, Philadelphia, PA) or its vehicle was given subcutaneously in two doses: $30 \mathrm{~min}(10 \mathrm{mg} / \mathrm{kg})$ and $1.0 \mathrm{~min}(5.0 \mathrm{mg} / \mathrm{kg})$ before the formalin injection. The opioid antagonist naltrexone, when used, was given subcutaneously $(10 \mathrm{mg}$ $\mathrm{kg}) 5 \mathrm{~min}$ before the first dose of morphine, that is, $35 \mathrm{~min}$ before the noxious stimulus.

Perfusion. At the end of the testing period, each animal was deeply anesthetized with a mixture of ketamine $(100 \mathrm{mg} / \mathrm{kg})$ and xylazine $(15$ $\mathrm{mg} / \mathrm{kg}$ ), and then perfused through the ascending aorta with $50 \mathrm{ml}$ of $0.05 \mathrm{M}$ phosphate-buffered $0.9 \%$ saline (PBS), followed by $750 \mathrm{ml}$ of

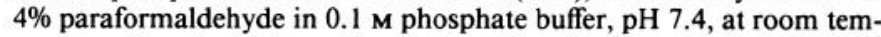
perature. Two hours later, the spinal cord and brainstem were removed and postfixed in the same fixative solution for $4 \mathrm{hr}$ at $4^{\circ} \mathrm{C}$. The tissues were then cryoprotected in a $30 \%$ solution of phosphate-buffered $(\mathrm{pH}$ 7.4) sucrose at $4^{\circ} \mathrm{C}$ for at least $48 \mathrm{hr}$ before sectioning.

Immunocytochemistry. Fifty-micrometer serial transverse sections of the injection site and of the lumbar spinal cord were cut on a freezing microtome. Every fourth section was immunostained. To visualize Foslike-immunoreactive neurons in the spinal cord, we used the avidinbiotin-peroxidase procedure (Hsu et al., 1981) as previously described (Presley et al., 1990). Sections of the lumbar cord were immersed in a blocking solution made of $3 \%$ normal goat serum (NGS) and $0.3 \%$ Triton X-100 in PBS for $1 \mathrm{hr}$ and then incubated for $48 \mathrm{hr}$ at $4{ }^{\circ} \mathrm{C}$ with a rabbit polyclonal antiserum directed against an in vitro translated protein product of the $c$-fos gene (courtesy of Dr. Dennis Slamon, Departments of Hematology and Oncology, UCLA) at a dilution of 1:21,000 in PBS, $1 \%$ normal goat serum, and $0.3 \%$ Triton. This antiserum does not recognize the Fos-related antigens. To reduce background staining, the antiserum was preabsorbed with acetone-dried rat liver powder for $1 \mathrm{hr}$ at $37^{\circ} \mathrm{C}$ and $2 \mathrm{hr}$ at $4^{\circ} \mathrm{C}$. After the primary antibody incubation, the tissue was exposed to a goat anti-rabbit biotinylated secondary IgG (Vector Labs, Burlingame, CA) diluted 1:200 and then to the ABC Elite complex (Vector Labs) for $1 \mathrm{hr}$ at room temperature. To visualize the Fos-like immunoreactivity as a black reaction product we used a nickeldiaminobenzidine (Nickel-DAB) glucose-oxidase reaction following a protocol adapted from Llewellyn-Smith and Minson (1992).

The same Fluoro-gold immunocytochemical procedure was used to identify injection sites (Figs. 1, 2) and retrogradely labeled neurons (Figs. $3,4)$. For double labeling, the Fos-immunoreacted sections were washed three times in Tris buffer with $1 \%$ NGS and $0.3 \%$ Triton and incubated with the blocking solution for $1 \mathrm{hr}$, and then overnight with a rabbit anti-Fluoro-gold polyclonal antiserum (Chemicon Inc., Temecula, CA) at a dilution of 1:5000-1:20,000, depending on the lot. After washing, the tissue was exposed to a goat anti-rabbit biotinylated secondary IgG and then to the $\mathrm{ABC}$ complex. The Fluoro-gold-like immunoreactivity was made visible by DAB reaction as described above, with the exclusion of nickel. The two immunocytochemical procedures resulted in a light brown staining of the cytoplasm of retrogradely labeled neurons that contrasted well with the black nuclei of the Fos-like-immunoreac- 

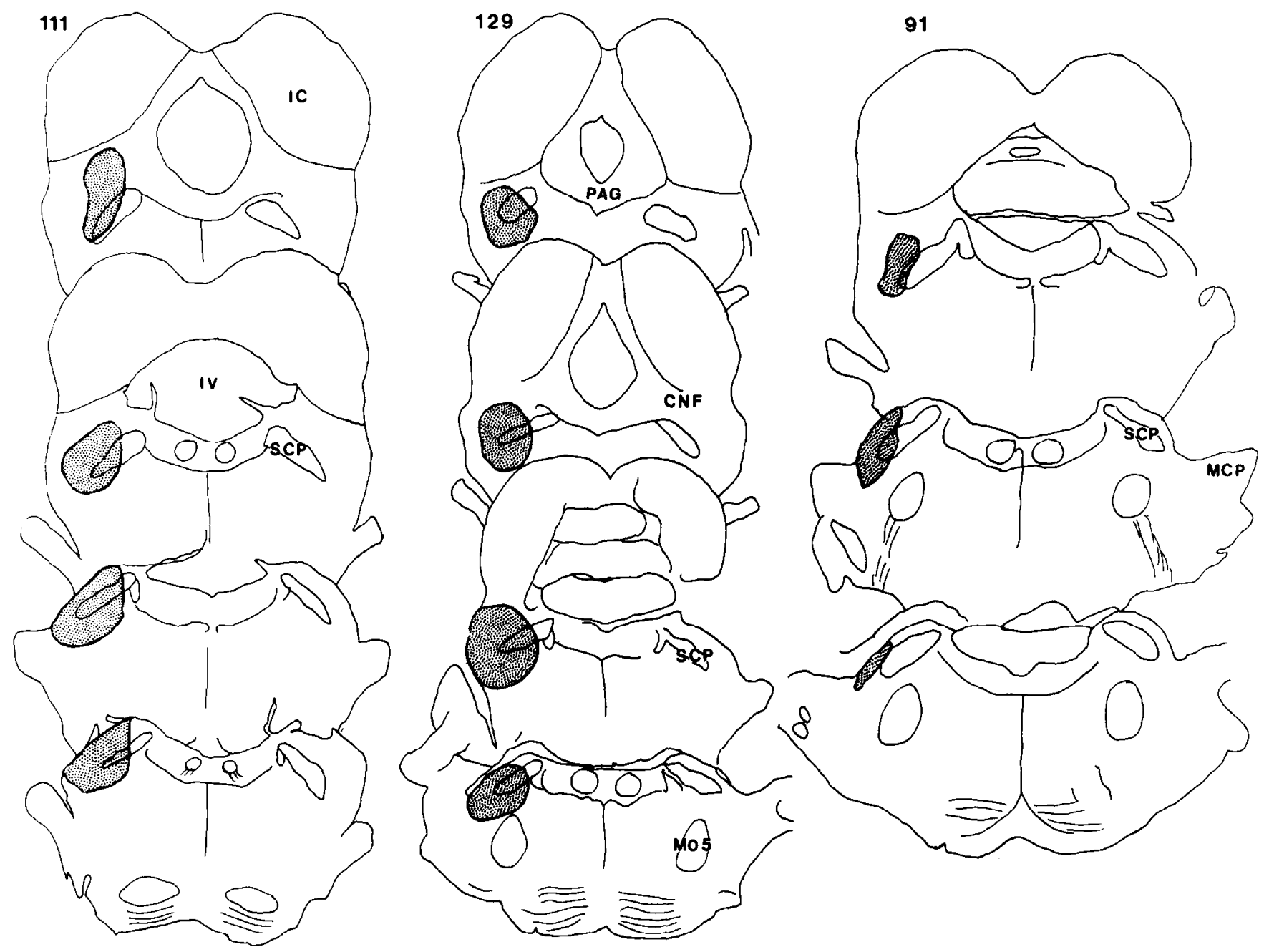

Figure 2. These camera lucida drawings of transverse sections show the extent of the Fluoro-gold injcctions in the parabrachial area in three representative cases, FL-111, FL-129, and FL-91. $C N F$, cuneiform nucleus; $I C$, inferior colliculus; $I V$, fourth ventricle; $M C P$, middle cerebellar peduncle; $M O 5$, motor nucleus of the trigeminal; $P A G$, periaqueductal gray matter; $S C P$, middle cerebellar peduncle.

tive neurons (Fig. 3) and allowed identification of double-labeled cells over a wide range of staining intensity for both antigens. Finally, sections were washed three times in Tris buffer, mounted from tap water on gelatin-coated slides, air dried, dehydrated in alcohol in graded manner, cleared in xylene, and coverslipped. The injection sites were visualized by reacting the brainstem sections with the anti-Fluoro-gold antiserum following the steps described above, and completing the procedure with a nickel-intensified DAB reaction.

Omitting the primary antiserum for the Fos protein or Fluoro-gold on control sections resulted in no signal for the corresponding antigen. For each antigen, comparison of cell counts made in single- and doublelabeled sections from the same animal confirmed that the double immunocytochemistry did not reduce the signal of individual antigens.

We used immunocytochemistry with an $\mathrm{ABC}$ technique, rather than fluorescence, to detect Fos and Fluoro-gold. Although fluorescence detection is simpler, the signal of Fos-like immunoreactivity after the $\mathrm{Ni}$ $\mathrm{DAB}$ reaction is much stronger than that seen after an indirect fluorescence method. Furthermore, immunostaining the Fluoro-gold makes double-labeled cells easier to detect under the microscope at both high and low magnification. In a preliminary study, we found that the fluorescence method led to an underestimation of the number of doublelabeled cells.

Mapping and cell counts. All drawings of sections were done under light microscopy, using a camera lucida attachment. The full extent of the injection site and the surrounding brainstem were mapped at low magnification $(4 \times)$. For the spinal cord, counts of single-labeled Fos or Fluoro-gold and double-labeled cells were made on six randomly se- lected $L_{4}-L_{5}$ sections for each of the 18 formalin-injected animals. The investigator responsible for plotting and counting the labeled cells was blind to the drug treatment of each animal. The following three regions of the spinal gray matter (Steiner and Turner, 1972; Molander et al., 1984) were delineated on the spinal cord drawing: (1) laminae I + Ilo, (2) reticulated area of the dorsal horn (delineated under dark-field illumination), and (3) the central canal area (lamina $X$ and adjacent portions of laminae V, VI, VII, and VIII; Fig. 4). These three lumbar cord regions contain the majority of the neurons that project to the parabrachial nucleus (PBN) (Menétrey and de Pommery, 1991). Although the lateral spinal nucleus also contained neurons that projected to the PBN, we excluded these neurons from the present analysis because few of these cells expressed $c$-fos in response to formalin. Nociresponsive neurons in laminae VII and VIII were also excluded because very few of these project to the PBN.

Since a quantitative study of double-labeled Fluoro-gold and Foslike-immunoreactive neurons has never been reported before, the strict criteria used to map single- and double-labeled cells will be described. A nucleus was counted as Fos positive if it was entirely filled by black reaction product. A cell body was counted as Fluoro-gold positive if the granular brown reaction product surrounded a nuclear area and filled the proximal dendrites. Fluoro-gold-like-immunoreactive cells whose nuclei contained a brown reaction product were occasionally seen, but were not considered to be double labeled since the nuclear immunoreactivity may have resulted from Fluoro-gold rather than Fos. All cells were identified, mapped, and counted at high magnification $(20-40 \times)$. For all animals, we express the extent of double labeling as a percentage 

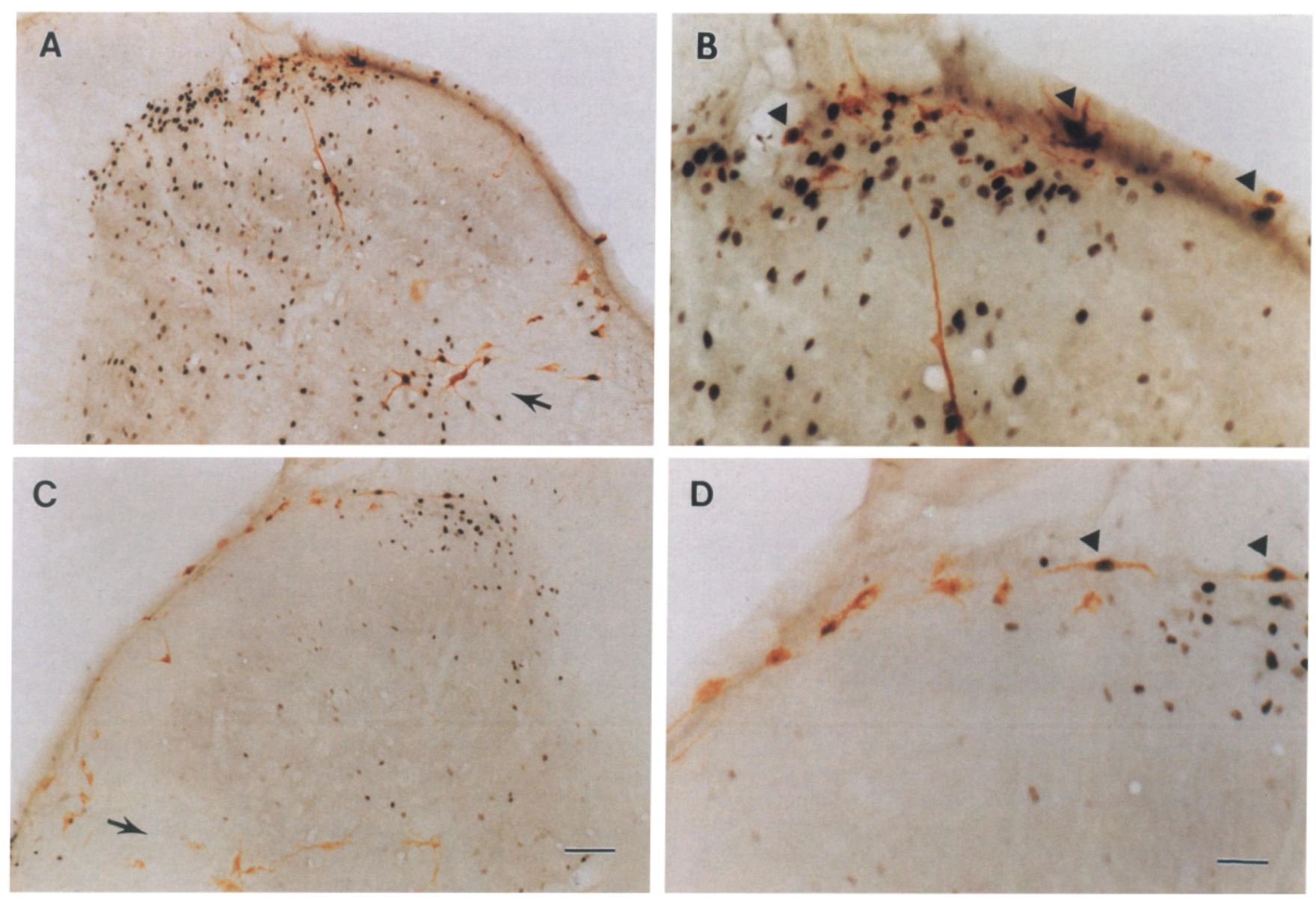

Figure 3. These photomicrographs are of representative sections that illustrate the distribution of Fos-immunoreactive (black) nuclei, Fluorogold-labeled spinoparabrachial projection (light brown) neurons, and double-labeled (Fos-immunoreactive/Fluoro-gold) neurons in the lumbar dorsal horn. The sections in $A$ and $B$ are from rat FL-137, which received saline prior to the hindpaw formalin stimulus. Double-labeled cells (arrowheads in $B$ and $D$ ) are present in the superficial dorsal horn (SDH) and in the reticulated area of the neck of the dorsal horn (RDH; arrows in $A$ and $C$ ). The sections in $C$ and $D$ are from rat FL-129, which received morphine prior to the formalin stimulus. Morphine significantly reduced the number of Fos-immunoreactive neurons in all regions, but reduced only the number of Fos-immunoreactive spinoparabrachial neurons in the reticulated area of the dorsal horn. Despite the great reduction in the number of Fos-immunoreactive neurons in the superficial dorsal horn, doublelabeled neurons are still readily detected (arrowheads in $B$ and $D$ ). Scale bars: $A$ and $C, 100 \mu \mathrm{m} ; B$ and $D, 38.5 \mu \mathrm{m}$.

of the total number of retrogradely labeled cells. This calculation corrects for differences in the absolute number of retrograde cells that probably resulted from differences in the location of the Fluoro-gold injection sites.

Statistical analysis. The results are presented as means \pm SEM. Statistical comparisons were performed using the Student's $t$ test (unpaired, two tailed) to compare the means of the two groups. Differences between means were considered statistically significant at $P<0.05$.

\section{Results}

Control experiments

As described previously (Presley et al., 1990), in unstimulated rats we typically record some lightly labeled Fos-like-immunoreactive neurons in laminae III and IV; these neurons are presumably driven by large-diameter primary afferent fibers that have cutaneous inputs. The same pattern was observed in the present study and, importantly, it did not differ in an animal that was injected in the parabrachial nucleus 1 week prior to perfusion but was not exposed to the noxious stimulus, or in the three animals that received morphine without the noxious stimulus. Thus, the presence of retrogradely transported Fluoro- gold in spinal neurons does not itself induce Fos-like immunoreactivity. Comparable results were previously obtained with a different retrograde tracer (Menétrey et al., 1989). Unless otherwise noted, the counts of labeled cells per $50 \mu \mathrm{m}$ section for the different spinal cord regions include only cells on the side contralateral to the Fluoro-gold injection.

\section{Injection sites in the parabrachial area}

In a preliminary study, we established that injections in the lateral parabrachial area produced more retrogradely labeled cells in the superficial dorsal horn than did injections in either the thalamus or the caudal medulla. Injections near to, but excluding, the lateral parabrachial area resulted in minimal retrograde labeling of cells in the superficial dorsal horn. Thus, we have analyzed only cases in which the injection site included part or all of the lateral parabrachial area (Fig. 1). Adjacent nuclei that were occasionally involved in the injection site were the ventral third of the inferior colliculus, the cuneiform nucleus, the dorsal nucleus of the lateral lemniscus, the principal sensory trigeminal nucleus, and lobule II of the cerebellum. Fibers of 


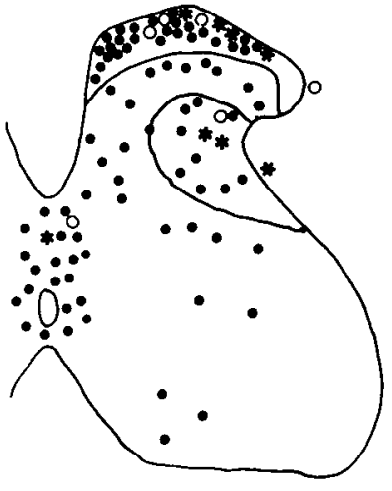

FL -107

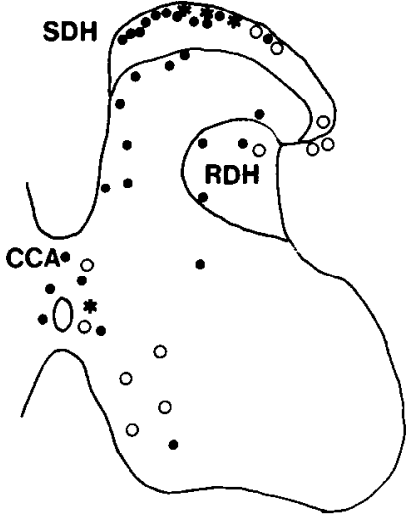

$F L-129$
Figure 4. These figures are camera lucida drawings of the distribution of spinoparabrachial (O), Fos-like-immunoreactive (FLI; 9 ), and double-labeled FLI-spinoparabrachial neurons $\left({ }^{*}\right)$ in sections of the $\mathrm{L}_{4}-\mathrm{L}_{5}$ spinal cord. The drawings illustrate the location of immunolabeling ipsilateral to a hindpaw injection of formalin and contralateral to the injection of retrograde tracer (Fluoro-gold) into the parabrachial nucleus. Results from two representative rats are illustrated: $F L-107$ received a saline injection prior to the formalin; $F L-129$ received morphine prior to formalin. Morphine markedly reduced $c$-fos expression in all regions of the spinal cord, but we found no effect on the number of FLI-spinoparabrachial projection neurons in the superficial dorsal horn $(S D H)$ or in the area around the central canal $(C C A)$. Morphinc reduced only the number of double-labeled projection neurons in the reticulated area of the neck of the dorsal horn $(R D H)$. One $O=1$ neuron; one $\bullet=5$ FLI neurons; one ${ }^{*}=1$ Fos-like-immunoreactive spinoparabrachial projection neuron.

passage in the superior cerebellar peduncle, the ventral spinocerebellar tract, and the lateral lemniscus were also frequently involved. To our knowledge, however, axons from the superficial dorsal horn do not course in these fiber tracts. Importantly, the injection sites never encroached upon the location of the spinothalamic tract, which is located more ventrally (H. J. Ralston III, personal communication).

\section{Distribution of Fluoro-gold-immunoreactive neurons}

With the exception of the lateral spinal nucleus, which was labeled on both sides of the spinal cord, Fluoro-gold-positive neurons predominated on the side of the spinal cord contralateral to the injection site, in the superficial dorsal horn, in the reticulated area of the dorsal horn, and in the area around the central canal. This is consistent with previous reports (Menétrey and de Pommery, 1991; Kitamura et al., 1993). The average number of Fluoro-gold-labeled cells per $50 \mu \mathrm{m}$ section of $\mathrm{L}_{4}-$ $L_{s}$ spinal cord was $7.4 \pm 0.6$ ipsilateral to the Fluoro-gold injection, and $18.0 \pm 1.0$ contralaterally $(n=20)$. With respect to the laminar distribution on the contralateral side, we recorded $6.2 \pm 0.3$ neurons in laminae I + IIo, and $3.1 \pm 0.2$ neurons in the reticulated area of the dorsal horn. There were $4.1 \pm 0.4$ neurons located bilaterally around the central canal. The other retrogradely labeled neurons were dispersed in the ventral and dorsal horns. Although Fluoro-gold-immunoreactive neurons in laminae I and Ilo were found throughout the mediolateral extent of the superficial dorsal horn, $80 \%$ were located in its middle third, where many were clustered under the dorsal root entry zone (Fig. 3). In the reticulated area of the dorsal horn, most of the retrogradely labeled cells were located laterally, at the junction of gray matter and white matter (Fig. 3).
Effect of formalin injection in control, saline-treated rats: behavior, Fos-like immunoreactivity, and double labeling from the parabrachial region

Fifteen seconds after the formalin injection the animals began to display the behavior that characterizes the first phase of the formalin test: flinching, shaking, licking and biting of the injected paw, and frequent movement within the observation area (Dubuisson and Dennis, 1977; Wheeler-Aceto and Cowan, 1991). After $5 \mathrm{~min}$, this behavior waned and gave way to a quiescent period during which the animals paid much less attention to the injected paw and had reduced locomotor activity compared to phase I. After 10-15 min, the second phase of the formalin test appeared; it was mainly characterized by the animal's tendency to avoid supporting weight on the affected paw. In control rats, this later phase continued until the end of the $1 \mathrm{hr}$ test period. Based on previous studies in which the pain behavior was scored (Gogas et al., 1991), this behavior corresponds to a rating of approximately 2.2 over the $1 \mathrm{hr}$ test period.

The distribution of Fos-like immunoreactivity in the lumbar cord of both the formalin-injected rats that received saline was similar to that described previously (Presley et al., 1990). We recorded the highest density of Fos-like-immunoreactive cells (117.0 \pm 8.1 neurons per $50-\mu \mathrm{m}$-thick transverse section) in the superficial dorsal horn ipsilateral to the formalin injection $(n=$ 6). Two-thirds of these cells were located in lamina I and the other third in lamina IIo. In both of these laminae, the majority of the Fos-like-immunoreactive cells was located in the medial half of the dorsal horn (Figs. 3, 4), where primary afferents from the sciatic nerve terminate (Swett and Woolf, 1985). Other Foslike-immunoreactive neurons in the ipsilateral spinal cord were located in the reticulated area of the dorsal horn $(74.0 \pm 13.8)$ and around the central canal $(63.2 \pm 14.0)$.

We recorded double-labeled, that is, Fluoro-gold- and Foslike-immunoreactive, neurons in all areas of the $L_{4}-L_{5}$ spinal segments that contained cells at the origin of the spinoparabrachial projection (Figs. 3, 4). In the superficial dorsal horn, 55.0 $\pm 5.6 \%$ of the retrogradely labeled cells were Fos-like immunoreactive. In the reticulated area of the dorsal horn and in the central canal area, $61.0 \pm 4.2 \%$ and $22.3 \pm 2.8 \%$, respectively, of the retrogradely labeled neurons were Fos-like immunoreactive. As expected from the fact that the percentage of labeled superficial dorsal horn (SDH) neurons rapidly falls off rostral and caudal to the $L_{4}-L_{5}$ segments, in the $L_{3}$ and $L_{6}$ segments we found an abrupt decrease in the percentage of projection neurons that were double labeled.

\section{Effect of morphine on formalin-evoked behavior, Fos-like immunoreactivity, and double labeling from the parabrachial region}

Morphine pretreatment completely blocked formalin-evoked pain behavior. Flinching and licking of the paw were absent and, despite the relatively high concentrations of morphine, the rats walked normally, bearing weight on all four limbs. Naltrexone given $5 \mathrm{~min}$ before the first dose of morphine, and 35 min before the formalin injection, reversed this analgesia. The pain behavior was similar to that seen in the formalin-injected rats that received saline pretreatment.

As described previously (Presley et al., 1990), morphine treatment significantly reduced the numbers of Fos-like-immunoreactive neurons in all regions; the largest relative decrease was in more ventral regions of the dorsal horn. In the $\mathrm{L}_{4}-\mathrm{L}_{5}$ spinal 
cord, ipsilateral to formalin injection, we recorded $25.7 \pm 2.8$ and $26.0 \pm 1.4$ Fos-like-immunoreactive cells in the reticulated area of the dorsal horn and in the central canal area, respectively $(n=10)$. This represented a significant $(p<0.01)$ reduction in labeling, relative to saline pretreated animals, of $65.0 \%$ in the reticulated area of the dorsal horn and $59.0 \%$ around the central canal. In the ipsilateral superficial dorsal horn we recorded 64.0 \pm 7.1 Fos-like-immunoreactive cells per section, which corresponds to a smaller $(45 \%)$ but still significant $(p<0.01)$ reduction in the number of Fos-like-immunoreactive cells with morphine. As in the saline-treated animals, two-thirds of the Fos-like immunoreactivity in the superficial dorsal horn was located in lamina I; the remainder was located in lamina IIo. In both laminae the highest concentration of labeling was in the medial half of the superficial dorsal horn (Figs. 3, 4). Finally, we found that the inhibitory effect of morphine on induction of Fos-like immunoreactivity by noxious stimulation was completely reversed by prior administration of the opioid receptor antagonist naltrexone ( $10 \mathrm{mg} / \mathrm{kg}, \mathrm{s.c}$; $n=2)$.

In contrast to the relatively uniform inhibition of $c$-fos expression in the superficial dorsal horn, in the reticulated area of the dorsal horn and in the area around the central canal we found a significant difference in the susceptibility of Fos-likeimmunoreactive spinoparabrachial projection neurons. Thus, relative to saline, morphine significantly $(p<0.01)$ decreased the percentage of projection neurons that were double labeled in the reticulated area of the dorsal horn $(35.7 \pm 6.6 \%)$. This represents an almost $50 \%$ reduction in the incidence of double labeling of projection neurons. By contrast, in neither the superficial dorsal horn nor in the area around the central canal did we record a change in the proportion of Fluoro-gold cells that were double labeled. In the $\mathrm{SDH}$, we found that $50.3 \pm$ $3.1 \%$ of the retrogradely labeled cells were double labeled after morphine treatment; the percentage of projection cells around the central canal that were double labeled after morphine was $17.3 \pm 2.2 \%$. For both these regions the percentages are not significantly different from what was found in the absence of morphine $(p>0.05)$. When naltrexone was coadministered with morphine, it not only reversed the inhibition of pain behavior but also rcversed the inhibition of $c$-fos expression in projection cells of the reticulated area of the dorsal horn.

\section{Discussion}

In this article we present evidence that two distinct populations of spinoparabrachial neurons can be recognized on the basis of their expression of the $c$-fos proto-oncogene in response to noxious stimulation (hindpaw formalin injection). In one population, located in the reticulated area of the dorsal horn, the expression of $c$-fos in spinoparabrachial neurons was significantly reduced by morphine. In contrast, there is a population of parabrachial projection neurons in the superficial dorsal horn and in the area around the central canal that continues to express the gene even though the dose of morphine used was sufficient to produce complete behavioral analgesia. Since morphine, by itself, does not evoke increases in c-fos expression in spinal cord neurons (Presley et al., 1990; present results), at least two possible explanations for our results can be proposed. First, the increased FLI in projection neurons raised the possibility that under conditions of morphine analgesia, nociresponsive spinoparabrachial cells still transmit information to the brainstem. This hypothesis is based on the evidence that increased $c$-fos expression parallels neuronal activity (evoked under physiolog- ical conditions in vivo, or by ligand interactions in vitro) (Hunt et al., 1987; Morgan et al., 1987; Dragunow and Faull, 1989; Menétrey et al., 1989; Bullitt, 1990; Sheng and Greenberg, 1990; Herdegen et al., 1991). The second hypothesis is based on the premise that neuronal activity and Fos expression are, in fact, dissociated in these neurons. That is, if activity in these neurons is blocked by the analgesic dose of morphine, it must be concluded that there are significant molecular consequences of noxious stimulation in some spinal cord neurons, even under conditions in which neuronal activity has been suppressed by opioids. Both of these possibilities have important relevance to the generation of pain and are discussed below.

\section{Retrograde labeling from the parabrachial area}

Although the technique of double labeling may have caused an artifactual reduction of either the number of retrogradely labeled or Fos-immunorcactive neurons, this is unlikely for two reasons. First, the distribution of retrogradely labeled cells that we found is identical to that previously reported for the spinoparabrachial neurons in the superficial dorsal horn, the lateral spinal nucleus, the reticulated area of the dorsal horn and adjacent white matter, and the area of the central canal (Cechetto et al., 1985; Panneton and Burton, 1985; Wiberg et al., 1987; Bernard et al., 1989; Hylden et al., 1989; Menétrey and de Pommery, 1991; Menétrey et al., 1992; Kitamura et al., 1993). Second, the average number of retrogradely labeled cells that we recorded per section was equivalent to the highest numbers reported with other tracers (Menétrey and de Pommery, 1991; Kitamura et al., 1993). We therefore believe that the pattern of labeling identified by immunocytochemical localization of Fluoro-gold provides an accurate measure of the number of neurons at the origin of the spinoparabrachial pathway. It is unlikely that we missed a subpopulation of spinoparabrachial neurons.

\section{What stimulates c-fos expression in spinoparabrachial neurons?}

Since both the pain behavior and the increased $c$-fos expression are prevented if the formalin injection is preceded by local anesthetic block of the peripheral nerve or by dorsal rhizotomy (Coderre et al., 1990; Abbadie et al., 1992), it is clear that primary afferent activity is required. Furthermore, since formalin selectively activates small-caliber primary afferent fibers, the majority of which are nociresponsive (Dickenson and Sullivan, 1987; Heapy et al., 1987), and since neonatal capsaicin treatment, which reduces the number of small-diameter primary afferent fibers, significantly decreases noxious stimulus-evoked expression of $c-f o s$ in the spinal cord (Hylden et al., 1992), we conclude that activation of small-diameter nociceptive primary afferents is necessary. Consistent with this conclusion, the distribution of Fos-like-immunoreactive neurons in the superficial dorsal horn is in the region of termination of small-diameter primary afferents from the tibial nerve (Woolf and Fitzgerald, 1986), which innervates the plantar aspect of the hindpaw where the formalin injection was made. In fact, light microscopic studies demonstrated that small-caliber primary afferents terminate on spinoparabrachial ncurons and clectrophysiological studies established that spinoparabrachial neurons in laminae I and IIo, and their target neurons in the parabrachial area, predominantly respond to noxious stimulation (Hylden et al., 1986; Light et al., 1987, 1993; Bernard and Besson, 1990; Nahin et al., 1991). Although some lamina I and IIo spinoparabrachial neurons respond to innocuous cooling (Light et al., 1993), it is unlikely 
that they are activated by the formalin stimulus; the latter is accompanied by hyperemia and thus raised temperature of the affected foot.

\section{The significance of $\mathrm{c}-\mathrm{fos}$ expression in spinoparabrachial neurons during morphine analgesia}

As indicated above, one interpretation of the maintained expression of the $c$-fos gene in subpopulations of spinoparabrachial neurons of rats rendered analgesic is that despite the morphine, some nociceptive information is still transferred to the brainstem. If these neurons are indeed active, what might be the consequence of this activity? Two possibilities can be considered.

First, it is possible that the output of laminae I, IIo, and X spinoparabrachial neurons is, in fact, pronociceptive, but that the information transmitted by this population of neurons, by itself, is not sufficient to generate pain behavior in the formalin test. Since there is evidence that the spinoparabrachial pathway provides nociceptive information to the circuitry that engages emotional behavior, via the connections of the parabrachial region with the amygdala (Bernard et al., 1993), it is conceivable that pain behavior is manifested only when activity in neurons of other pathways such as the spinothalamic tract occurs simultaneously. That is, the output of nociresponsive spinal cord neurons whose activity is blocked by morphine may provide the discriminative aspect of the nociceptive message that is integrated at supraspinal sites with the "affective" component of the message that is transmitted by the spinoparabrachialamygdala pathway.

It is, of course, also possible that the output of these subpopulations of spinoparabrachial neurons contributes to the pain behavior, but that morphine blocks information transfer from these neurons at higher levels of the neuraxis, in the parabrachial area itself, or in the amygdala. The presence of a high density of $\mu$-opioid receptors in the dorsal parabrachial area (Xia and Haddad, 1991) and the fact that systemic morphine markedly depresses the firing of parabrachioamygdaloid projection neurons in response to a noxious stimulus (Huang et al., 1993) are consistent with this hypothesis.

The central canal area, where many double-labeled cells werc seen in morphine-treated animals, receives a dense visceral afferent input, and many neurons in this region respond to noxious stimulation and to visceral afferent inputs (Honda, 1985; Honda and Perl, 1985). There is considerable evidence that the spinoparabrachial projection is involved in the generation of autonomic reflexes. For example, a stressful stimulus induces $c$-fos expression in neurons of the parabrachial region (Ceccatelli et al., 1989). Stimulation of the lateral parabrachial area, where viscerosensory relay neurons are found (Herbert et al., 1990; Jhamandas et al., 1991), evokes a variety of autonomic responses (Mraovitch et al., 1982; Ward, 1988; Dick et al., 1992; Jhamandas and Harris, 1992; Takayama and Miura, 1993), which suggests that activation of this area initiates autonomic reflex responses to noxious stimulation. The extent to which these reflexes are blocked by an analgesic dose of morphine was not tested in our studies. Conceivably, the autonomic and sensory discriminative consequences of a noxious stimulus are differentially regulated by opiates in the formalin paradigm. The fact that many projection neurons in the central canal area expressed $c$-fos under conditions of morphine analgesia is also consistent with this view.

A corollary of the first hypothesis is that these nociresponsive spinoparabrachial ncurons do not normally contribute to the pain behavior that is evoked by a noxious stimulus. Rather, under physiological conditions, that is, in the absence of exogenously administered opioids, activity in these neurons may activate descending antinociceptive circuits that originate in the PAG or in the anterior pretectal nucleus (Basbaum and Fields, 1984; Rees and Roberts, 1993); that is, they might engage antinociceptive circuits as part of a negative feedback system that is activated by noxious stimulation. Anterograde tracing studies of parabrachial projections have, in fact, demonstrated a significant projection to the PAG (J. F. Bernard, personal communication) and retrograde tracer injections in the anterior pretectal nucleus label neurons in the lateral parabrachial area (Foster et al., 1989). The output of the spinoparabrachial neurons would enhance the antinociceptive controls induced by morphine. Since such a system would be counterproductive if the spinoparabrachial neurons that trigger descending controls were themselves inhibited from the brainstem, to operate effectively these spinoparabrachial neurons would have to be less susceptible to descending inhibitory controls. Mokha (1993), in fact, recorded from nociresponsive neurons in the medullary dorsal horn and found that while systemic morphine uniformly inhibited the firing of neurons in the region of lamina $V$, it enhanced the activity of onc-third of neurons located in the superficial laminae. McMahon and Wall (1988) also reported on a population of neurons in the superficial dorsal horn that are excited by electrical stimulation of the dorsolateral funiculus (DLF), the pathway through which many descending inhibitory controls are exerted. This population of neurons may correspond to the spinoparabrachial neurons that we identified in the present study.

The second interpretation of our results is diametrically apposed to the first. It follows from the assumption that neuronal activity in all populations of spinoparabrachial neurons is blocked by morphine, but that noxious stimulus-evoked $c$-fos expression in subpopulations persists. Conceivably, the primary afferent neurotransmitter-evoked changes in postsynaptic $\mathrm{Ca}^{2+}$ levels can induce $c$-fos expression, and all of the molecular changes secondary to the increased amount of Fos protein, even though the membrane potential change produced is not sufficient to induce activity. The implications of this mechanism are significantly different from that described above. Specifically, since the production of the Fos protein is but the first step in a cascade of molecular changes in the neuron (only a few of which have been identified; e.g., Naranjo et al., 1991), these results indicate that noxious stimuli can evoke long-term changes in neurons even though activity in the neuron is blocked.

Recent studies have demonstrated that noxious stimulation can, in fact, evoke a long-term sensitization of dorsal horn neurons. These changes require activity of C-fiber primary afferents and can be blocked by the NMDA antagonist MK-801 (Woolf and Thompson, 1991). Among the long-term changes recorded are increased receptive field size and lowered threshold to subsequent stimulation. Since $c$-fos induction may contribute to these changes, the possibility must be considered that such noxious stimulus-evoked changes can be induced in dorsal horn neurons even when the behavioral and electrophysiological consequences of the stimulus are blocked by morphine.

How could morphine block neuronal activity in these neurons, without blocking the expression of the $c$-fos gene? Although there is evidence that morphine can presynaptically inhibit inputs to dorsal horn neurons, by blocking the release of primary afferent neurotransmitters (Suarez-Roca and Maixner, 1992), it 
is unlikely that this mechanism operates upon these neurons. A presynaptic action of morphine would presumably prevent both the neurotransmitter-evoked activity and $c$-fos induction. It follows that the predominant inhibitory effect of morphine on these neurons must be postsynaptic, that is, hyperpolarization without blockade of $c$-fos induction.

\section{Summary}

Our results indicate that under conditions of morphine analgesia two distinct populations of spinoparabrachial neurons can be recognized on the basis of their expression of the $c$-fos gene in response to noxious stimulation. Morphine blocked noxious stimulus-evoked $c$-fos expression in spinoparabrachial projection neurons concentrated in the neck of the dorsal horn. Morphine was without effect on the expression of $c$-fos in spinoparabrachial projection neurons of the superficial dorsal horn and in the area around the central canal. Our interpretation of the increased production of the Fos protein in nociresponsive neurons during morphine analgesia depends on the relationship of neuronal activity to $c$-fos expression. Either spinal nociceptive transmission in subpopulations of neurons can persist during morphine analgesia, or the present results could be indicative of long-term molecular changes in nociresponsive neurons even though neuronal activity is blocked.

\section{References}

Abbadie C, Lombard MC, Morain F, Besson JM (1992) Fos-like immunoreactivity in the rat superficial dorsal horn induced by formalin injection in the forepaw: effects of dorsal rhizotomies. Brain Res 578: $17-25$.

Aimone LD, Yaksh TL (1989) Opioid modulation of capsaicin-evoked release of substance $P$ from rat spinal cord in vivo. Peptides 10:11271131.

Basbaum AI, Fields HL (1984) Endogenous pain control systems: brainstem spinal pathways and endorphin circuitry. Annu Rev Neurosci 7:309-338.

Bernard JF, Besson JM (1990) The spino(trigemino)pontoamygdaloid pathway: electrophysiological evidence for an involvement in pain processes. J Neurophysiol 63:473-490.

Bernard JF, Peschanski M, Besson JM (1989) A possible spino (trigemino)-ponto-amygdaloid pathway for pain. Neurosci Lett 100:8388.

Bernard JF, Alden M, Besson JM (1993) The organization of the efferent projections from the pontine parabrachial area to the amygdaloid complex: a Phaseolus vulgaris leucoagglutinin (PHA-L) study in the rat. J Comp Neurol 329:201-229.

Brennan PA, Hancock D, Keverne EB (1992) The expression of the immediate-early genes c-fos, egr- 1 and c-jun in the accessory olfactory bulb during the formation of an olfactory memory in mice. Neuroscience 49:277-284

Bullitt E (1990) Expression of C-fos-like protein as a marker for neuronal activity following noxious stimulation in the rat. J Comp Neurol 296:517-530.

Bullitt E (1991) Somatotopy of spinal nociceptive processing. J Comp Neurol 312:279-290.

Campeau S, Hayward MD, Hope BT, Rosen JB, Nestler EJ, Davis M (1991) Induction of the c-fos proto-oncogene in rat amygdala during unconditioned and conditioned fear. Brain Res 565:349-352.

Ceccatelli S, Villar MJ, Goldstein M, Hökfelt T (1989) Expression of c-Fos immunoreactivity in transmitter-characterized neurons after stress. Proc Natl Acad Sci USA 86:9569-9573.

Cechetto DF, Standaert DG, Saper CB (1985) Spinal and trigeminal dorsal horn projections to the parabrachial nucleus in the rat. J Comp Neurol 240:153-160.

Coderre TJ, Vaccarino AL, Melzack R (1990) Central nervous system plasticity in the tonic pain response to subcutaneous formalin injection. Brain Res 535:155-158.

Dick TE, Haxhiu MA, Cherniack NS (1992) Salivary secretion elicited by activation of the parabrachial nuclei in the cat. J Auton Nerv Syst $39: 19-28$
Dickenson AH, Sullivan AF (1987) Subcutaneous formalin-induced activity of dorsal horn neurones in the rat: differential response to an intrathecal opiate administered pre or post formalin. Pain 30:349360.

Dragunow M, Faull R (1989) The use of c-fos as a metabolic marker in neuronal pathway tracing. J Neurosci Methods 29:261-265.

Dubuisson D, Dennis SG (1977) The formalin test: a quantitative study of the analgesic effects of morphine, meperidine, and brain stem stimulation in rats and cats. Pain 4:161-174.

Foster GA, Sizer AR, Rees H, Koberts MH (1989) Afferent projections to the rostral anterior pretectal nucleus of the rat: a possible role in the processing of noxious stimuli. Neuroscience 29:685-694.

Gogas KR, Presley KW, Levine JD, Basbaum AI (1991) The antinociceptive action of supraspinal opioids results from an increase in descending inhibitory control: correlation of nociceptive behavior and c-fos expression. Neuroscience 42:617-628.

Heapy CG, Jamieson A, Russell NJW (1987) Afferent C-fibre and A-delta activity in models of inflammation. Br J Pharmacol 90:164P.

Herbert H, Moga MM, Saper CB (1990) Connections of the parabrachial nucleus with the nucleus of the solitary tract and the medullary reticular formation in the rat. J Comp Neurol 293:540-580.

Herdegen T, Kovary K, Leah J, Bravo R (1991) Specific temporal and spatial distribution of JUN, FOS, and KROX-24 proteins in spinal neurons following noxious transsynaptic stimulation. J Comp Neurol 313:178-191.

Honda CH, Perl ER (1985) Functional and morphological features of neurons in the midline region of the caudal spinal cord of the cat. Brain Res 340:285-295.

Honda CN (1985) Visceral and somatic afferent converge onto neurons near the central canal in the sacral spinal cord of the cat. J Neurophysiol 53:1059-1078.

Hsu S-U, Raine L, Fanger H (1981) Use of avidin-biotin-peroxidase complex $(\mathrm{ABC})$ in immunoperoxidase techniques: a comparison between $\mathrm{ABC}$ and unlabeled antibody procedure. J Histochem Cytochem 29:577-580.

Huang GF, Besson JM, Bernard JF (1993) Morphine depresses the transmission of noxious messages in the spino(trigemino)-pontoamygdaloid pathway. Eur J Pharmacol 230:279-284.

Hunt PS, Pini A, Evan G (1987) Induction of c-fos-like protein in spinal cord neurons following sensory stimulation. Nature 328:632634.

Hylden JLK, Wilcox GL (1986) Antinociceptive effect of morphine on rat spinothalamic tract and other dorsal horn neurons. Neuroscience 119:393-401.

Hylden JLK, Hayashi H, Dubner R, Bennett GJ (1986) Physiology and morphology of the lamina I spinomensencephalic projection. $J$ Comp Neurol 247:505-515.

Hylden JLK, Anton F, Nahin RL (1989) Spinal lamina I projection neurons in the rat: collateral innervation of parabrachial area and thalamus. Neuroscience 28:27-37.

Hylden JLK, Noguchi K, Ruda MA (1992) Neonatal capsaicin treatment attenuates spinal fos activation and dynorphin gene expression following peripheral tissue inflammation and hyperalgesia. J Neurosci 12:1716-1725.

Jasmin L, Gogas KR, Ahlgren SC, Levine JD, Basbaum Al (1994) Walking evokes a distinctive pattern of Fos-like immunoreactivity in the caudal brainstem and spinal cord of the rat. Neuroscience 58: 275-286.

Jhamandas JH, Harris KH (1992) Influence of nucleus tractus solitarius stimulation and baroreceptor activation on rat parabrachial neurons. Brain Res Bull 28:565-571.

Jhamandas JH, Harris KH, Krukoff TL (1991) Parabrachial nucleus projections towards the hypothalamic supraoptic nucleus: electrophysiological and anatomical observations in the rat. J Comp Neurol 308:42-50.

Jurna I, Grossman W (1976) The effect of morphine on the activity evoked in ventrolateral tract axons of the cat spinal cord. Exp Brain Res 24:473-484.

Kitamura T, Yamada J, Sato H, Yamashita K (1993) Cells of origin of the spinoparabrachial fibers in the rat: a study with fast blue and WGA-HRP. J Comp Neurol 328:449-461.

Light AR, Casale E, Sedivec M (1987) The physiology and anatomy of spinal laminae I and II neurons antidromically activated by stimulation in the parabrachial region of the midbrain and pons. In: Fine 
afferent nerve fibers and pain (Schmidt RF, Schaible HG, Vahle-Hinz C, eds), pp 349-356. Weinheim: Verlagsgesellschaft.

Light AR, Sedivec MJ, Casale EJ, Jones SL (1993) Physiological and morphological characteristics of spinal neurons projecting to the parabrachial region of the cat. Somatosens Mot Res 10:309-325.

Llewellyn-Smith IJ, Minson JB (1992) Complete penetration of antibodies into vibratome sections after glutaraldehyde fixation and ethanol treatment: light and electron microscopy for neuropeptides. J I listochem Cytochem 40:1741-1749.

McMahon SB, Wall PD (1988) Descending excitation and inhibition of spinal cord lamina I projection neurons. J Neurophysiol 59:12041219.

Menétrey D (1987) Spinal nociceptive neurons at the origin of long ascending pathways in the rat: electrophysiological, anatomical and immunohistochemical approaches. In: Thalamus and pain (Besson J-M, Guilbaud G, Peschanski M, eds), pp 21-34. New York: Elsevier. Menétrey D, de Pommery J (1991) Origins of spinal ascending pathways that reach central areas involved in visceroception and visceronociception in the rat. Eur J Neurosci 3:249-259.

Menétrey D, Gannon A, Levine JD, Basbaum AI (1989) Expression of $\mathrm{c}$-fos protein in interneurons and projection neurons of the rat spinal cord in response to noxious somatic, articular, and visceral stimulation. J Comp Ncurol 285:177-195.

Menétrey D, de Pommery J, Thomasset M, Baimbridge KG (1992) Calbindin-D28K (CaBP28k)-like immunoreactivity in ascending projections. II. Spinal projections to brain stem and mesencephalic areas. Eur J Neurosci 4:70-76.

Mokha SS (1993) Morphine differentially modulates nociceptive input in the superficial versus the deeper dorsal horn of the medulla (trigeminal nucleus caudalis) in the rat. Brain Res 626:318-321.

Molander C, Xu Q, Grant G (1984) The cytoarchitectonic organization of the spinal cord in the rat. I. The lower thoracic and lumbosacral cord. J Comp Neurol 230:133-141.

Morgan JI, Cohen DR, Hempstead JL, Curran T (1987) Mapping pattern of $c$-fos expression in the central nervous system after seizure. Science 237:192-197.

Mraovitch S, Kumada M, Rcis DJ (1982) Role of the nuclcus parabrachialis in cardiovascular regulation in cat. Brain Res 232:57-75.

Nahin RL, Humphrey E, Hylden JLK (1991) Evidence for calcitonin gene-related peptide contacts on a population of lamina I projection neurons. J Chem Neuroanat 4:123-129.

Naranjo JR, Mellström B, Achaval M, Sassone-Corsi P (1991) Molecular pathways of pain: Fos/Jun-mediated activation of a noncanonical AP-1 site in the prodynorphin gene. Neuron 6:607-617.

Panneton WM, Burton H (1985) Projections from the paratrigeminal nucleus and the medullary and spinal dorsal horns to the peribrachial area in the cat. Neuroscience 15:779-797.

Paxinos G, Watson C (1986) The rat brain in stereotaxic co-ordinates. New York: Academic.
Presley RW, Menêtrey D, Levine JD, Basbaum AI (1990) Systemic morphine suppresses noxious stimulus-evoked Fos protein-like immunoreactivity in the rat spinal cord. J Neurosci 10:323-335.

Rees H, Roberts MHT (1993) The anterior pretectal nucleus: a proposed role in sensory processing. Pain 53:121-135.

Schmued LC, Fallon JH (1986) Fluoro-gold: a new fluorescent retrograde axonal tracer with numerous unique properties. Brain Res 377:147-154.

Sheng M, Grecnberg ME (1990) The regulation and function of c-fos and other immediate early genes in the nervous system. Neuron 4:477485.

Steiner TJ, Turner LM (1972) Cytoarchitecture of the rat spinal cord. J Physiol (Lond) 222:123P-125P.

Suarez-Roca H, Maixner W (1992) Morphine produces a multiphasic effect on the release of substance $P$ from rat trigeminal nucleus slices by activating different opioid receptor subtypes. Brain Res 579:195203.

Swett JE, Woolf CJ (1985) The somatotopic organization of primary afferent terminals in the superficial laminae of the dorsal horn of the rat spinal cord. J Comp Neurol 231:66-77.

Takayama K, Miura M (1993) Respiratory responses to microinjection of excitatory amino acid agonists in ventrolateral regions of the lateral parabrachial nucleus in the cat. Brain Res 604:217-223.

Traub RJ, Pechman P, Iadarola MJ, Gebhart GF (1992) Fos-like proteins in the lumbosacral spinal cord following noxious and nonnoxious colorectal distention in the rat. Pain 49:393-403.

Ward DG (1988) Stimulation of the parabrachial nuclei with monosodium glutamate increases arterial pressure. Brain Res 462:383-390.

Wheeler-Aceto H, Cowan A (1991) Standardization of the rat formalin test for the evaluation of analgesics. Psychopharmacology 104:35-44.

Wiberg M, Westman J, Blomqvist A (1987) Somatosensory projection to the mesencephalon: an anatomical study in the monkey. J Comp Neurol 264:92-117.

Willcockson WS, Chung JM, Hori Y, Lee KH, Willis WD (1984) Effects of iontophoretically released peptides on primate spinothalamic tract cells. J Neurosci 4:741-750.

Woolf CJ, Fitzgerald M (1986) Somatotopic organization of cutaneous afferent terminals and dorsal horn neuronal receptive fields in the superficial and deep laminae of the rat lumbar spinal cord. J Comp Neurol 251:517-531.

Woolf CJ, Thompson SWN (1991) The induction and maintenance of central sensitization is dependent on $N$-methyl-D-aspartic acid receptor activation: implications for the treatment of post-injury pain hypersensitivity states. Pain 44:293-299.

Xia Y, Haddad GG (1991) Ontogeny and distribution of opioid receptors in the rat brainstem. Brain Res 549:181-193.

Yaksh TL, Noueihed R (1985) The physiology and pharmacology of spinal opiates. Annu Rev Pharmacol Toxicol 25:433-462. 